\title{
Clinical Trial of a New Glass lonomer for an Atraumatic Restorative Treatment Technique in Class I Restorations Placed in Latvian School Children
}

\author{
Armands Ziraps a Eino Honkala ${ }^{b, c}$ \\ aDepartment of Operative Dentistry, Institute of Stomatology, Medical Academy of Latvia, Riga, Latvia; \\ bHelsinki International Institute for Oral Health, University of Helsinki, Finland; cFaculty of Dentistry, \\ Kuwait University, Kuwait
}

\section{Key Words}

Dentistry, operative - Glass ionomer · Atraumatic restorative treatment

\begin{abstract}
Objective: The aim of this study was to evaluate the performance of a new glass ionomer filling material (ChemFlex $^{\mathrm{TM}}$ ) using the atraumatic restorative treatment (ART) approach in class I cavities in the permanent dentition of Latvian schoolchildren. Methods: A total of 63 fillings (40 test and 23 control) were placed using the ART technique in 41 schoolchildren in Riga at the Stomatology Institute of the Medical Academy of Latvia. These fillings were then blindly assessed after 2 years. Results: The complete success rate for both the test and the control material fillings were 92.5 and $94.9 \%$, respectively. Conclusion: The new glass ionomer filling has shown a good performance in terms of retention, marginal failure and fractures in class I cavities.
\end{abstract}

\section{Copyright $\odot 2002$ S. Karger AG, Basel}

\section{Introduction}

Chemically cured glass ionomer fillings are widely used for a variety of indications, and their clinical performances is well documented [1]. Because of the nature of glass ionomers with properties such as fluoride release, chemical bonding to the tooth structure, biocompatibility and applicability in clinical situations where other materials might not be suitable [2], they are the most appropriate materials for the atraumatic restorative treatment (ART) approach. This approach was developed in the mid-1980s, and it is based on excavating carious cavities in teeth using hand instruments only. In this approach, fillings are restored with a glass ionomer [3], with a consistency that allows a simplified application technique and a sufficient strength to restore permanent teeth in an early stage of caries. Frencken et al. [4] have shown excellent results at a 1-year evaluation of ART restorations, where a survival rate of $93 \%$ was found for one-surface fillings and an absence of caries was observed in teeth restored with ART. Evaluation after 2 and 3 years showed success rates of 89 and 85\% [5-8]. In another study [9], one-surface ART restorations were compared to one-surface amalgam restorations in the permanent dentition. After the evaluation period of 3 years, a statistically significant difference $(\mathrm{p}<$ 0.001 ) was observed, showing that amalgam restorations performed better than ART restorations. The restorative material used in that study was not specifically designed for the ART technique and the survival rates might have been improved with a different glass ionomer. The early results of the ART studies have been promising, but improvements in performance and longevity of fillings are still being sought. In a later study, Mandari et al. [10] did

\begin{tabular}{ll}
\hline KARGER & ( ) 2002 S. Karger AG, Basel \\
Fax +4161306 1234 & 1011-7571/02/0115-0044\$18.50/0 \\
$\begin{array}{l}\text { E-Mail karger@karger.ch } \\
\text { www.karger.com }\end{array}$ & $\begin{array}{l}\text { Accessible online at: } \\
\text { www.karger.com/journals/mpp }\end{array}$
\end{tabular}

Dr. Armands Ziraps

Department of Operative Dentistry, Institute of Stomatology

Medical Academy of Latvia, 20 Dzirciema Street

LV-1007 Riga (Latvia)

Tel. +371 9299545, Fax +371 7815323, E-Mail aziraps@latnet.lv 
Fig. 1. The number of fillings by different teeth and material.

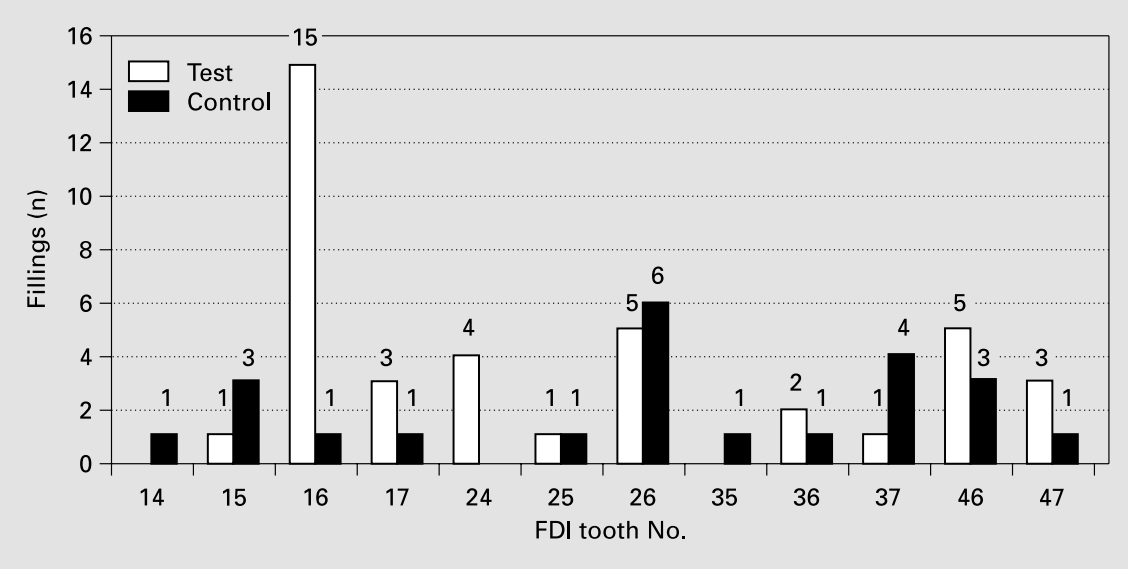

not find a statistically significant difference between onesurface amalgam and glass ionomer fillings after 2 years.

Recently, a new glass ionomer filling (Chem Flex ${ }^{\mathrm{TX}}$ ), Densply) has been introduced with improvements in mechanical strength and better handling properties, which has been achieved by a modified formulation. The improved mechanical strength is expected to increase the range of indications for this material, making it suitable for the ART approach in class I cavities. The improved material has been successfully evaluated in laboratory tests [11] and is ready for clinical investigation. Luo et al. [12] have shown success rates of $96.6 \%$ for ChemFlex and $89.9 \%$ for Fuji IX ${ }^{\mathrm{TM}}$ GP for ART restorations in class I in the primary teeth. For ART restorations in the permanent dentition, the success rates were 94.6 and $98.2 \%$ for ChemFlex and Fuji IX GP, respectively. The authors did not find any statistically significant difference between the two materials for either the permanent or primary teeth.

The aim of this study was to determine the efficacy of the new glass ionomer filling for providing retention and resistance to marginal failure and fracture when used for the restorations of class I cavities with the ART approach in the permanent dentition.

\section{Materials and Methods}

This study was conducted at the Stomatology Institute of the Medical Academy of Latvia, Riga, Latvia. All the subjects were secondary schoolchildren from the same school, the 69th Secondary School, Riga, except for 2 subjects from the 49th Secondary School and Barbins Christian School, Riga. The subjects were assessed as being generally healthy and had no complicating medical history.
Clinical examinations and operative procedures were done by an experienced dentist.

Altogether 196 children were examined (aged 7-14 years), and 74 children were considered as having primary carious lesions in the permanent dentition. The caries status was recorded according to criteria used in previous ART studies [5]. Some parents did not sign the informed consent ( 23 children), and 7 children did not show up for the clinical examination. Teeth with identifiable pulpal inflammation or with pain before treatment were not included in the study. No teeth that had partial or full root canal treatment were included, nor were those that had been subjected to direct pulp capping. In clinical examination, the 3 children found to have pulpal inflammation were excluded from the study. After screening, 41 children were enrolled in the study; their ages varied from 8 to 14 years (mean 11 years). They were randomly allocated to the control and test groups. A total of 63 restorations were placed (fig. 1). The test group comprised 40 restorations and the control group 23, respectively. In the control group, Fuji IX (GC Corporation) glass ionomer was used, as it was shown to be suitable for ART restorations [2, 13, 14].

All the operative procedures and cavity pretreatment, application of the materials, contouring and finishing were done according to the guidelines of the ART approach [3] and the manufacturer's instructions for use of the filling material. According to the guidelines of the ART approach [3], sealing neighbouring fissures is recommended and therefore this material was used as a sealant at the time of the ART restorations. The teeth were treated without local anaesthesia. An operator interviewed the patients immediately after placement of a restoration to establish whether the restored tooth/teeth had symptoms of discomfort/pain during the treatment. The subject's answers were documented on the standard ART technique questionnaire. Each restoration was drawn on a special ART form for clinical studies of the ART technique and material.

The double-blind evaluations were undertaken in a dental unit using the standard operating light, a mirror, an explorer and a WHO periodontal probe by an independent examiner experienced in the ART approach. Parameters for evaluating the quality of the restorations were retention, marginal integrity and wear according to the recommended codes used for evaluating ART restorations [3, 15] (table 1).

The data were analysed using the SPSS 8.0 analysis software using the sign test. 
Table 1. Evaluation criteria for ART restorations

\begin{tabular}{ll}
\hline Score & Criterion \\
\hline 0 & $\begin{array}{l}\text { present, good } \\
\text { present, slight marginal defect, which is less than } 0.5 \mathrm{~mm} \text { in } \\
\text { depth; no need for repair } \\
\text { present, marginal defect more than } 0.5 \mathrm{~mm} \text { in depth; repair } \\
\text { is needed } \\
\text { present, gross defect of more than } 1 \mathrm{~mm} \text { in depth; repair is } \\
\text { needed }\end{array}$ \\
$\begin{array}{l}\text { not present, restoration has (almost) completely } \\
\text { disappeared; treatment is needed }\end{array}$ \\
$\begin{array}{l}\text { not present; other restorative treatment has been performed } \\
\text { not present; tooth has been extracted } \\
\text { present, wear and tear gradually over large parts of the } \\
\text { restoration but it is less than } 0.5 \mathrm{~mm} \text { at the deepest point; } \\
\text { no repair is needed } \\
\text { present, wear and tear gradually over large parts of the } \\
\text { restoration which is deeper than } 0.5 \text { mm; repair is needed }\end{array}$ \\
\hline
\end{tabular}

Scores: $0,1,7=$ success; $2,3,4,5,6,8=$ failure.

Table 2. Performance of the control and the test restorations of class I cavities

\begin{tabular}{|c|c|c|c|c|}
\hline \multirow{2}{*}{$\begin{array}{l}\text { Description } \\
\text { code }\end{array}$} & \multicolumn{2}{|c|}{ Control } & \multicolumn{2}{|c|}{ Test } \\
\hline & $\mathrm{n}$ & $\%$ & $\mathrm{n}$ & $\%$ \\
\hline Success 0 & 15 & 83.3 & 18 & 66.7 \\
\hline Success 1 & - & & 1 & 3.6 \\
\hline Failure 2 & - & & 1 & 3.7 \\
\hline Failure 3 & - & & - & \\
\hline Failure 4 & 1 & 5.6 & - & \\
\hline Failure 5 & - & & 1 & 3.7 \\
\hline Success 6 & - & & - & \\
\hline Success 7 & 2 & 11.1 & 6 & 22.2 \\
\hline Total & 18 & & 27 & \\
\hline
\end{tabular}

\section{Results}

Of the 41 children initially enrolled in the study, 5 did not show up for the 2-year assessment. Therefore, only 55 $(87.3 \%)$ of the 63 glass ionomer fillings were assessed. There were 45 class I restorations, involving 27 test and 18 control materials. Of the test material, there were 25 successful restorations (92.5\%) and 2 failures (7.4\%). For the control group, 17 (94.9\%) of the restorations were successful; 7 (5.6\%) failed. The outcome of the restorations is presented in table 2 . No statistically significant difference was found between the two restorative materials.

The sealant part of the fillings was assessed separately. Over the 2-year period, the performance of sealants was
Table 3. Performance of sealants by the control and the test materials

\begin{tabular}{lccccc}
\hline $\begin{array}{l}\text { Description } \\
\text { code }\end{array}$ & \multicolumn{2}{c}{ Control } & & \multicolumn{2}{l}{ Test } \\
\cline { 2 - 3 } \cline { 5 - 6 } \cline { 5 - 6 } & $\mathrm{n}$ & $\%$ & & $\mathrm{n}$ & $\%$ \\
\hline Success 0 & 14 & 77.8 & & 20 & 66.7 \\
Success 1 & - & & 1 & 3.3 \\
Failure 4 & 4 & 22.2 & & 9 & 30 \\
\hline Total & 18 & & 30 & \\
\hline
\end{tabular}

not as good as that of the fillings. The test and control sealants showed $21(70 \%)$ and $14(77.8 \%)$ complete retentions, respectively, and $9(30 \%)$ and $4(22.2 \%)$ were completely lost (table 3 ). No statistically significant difference was found.

None of the children had experienced postoperative sensitivity or any other disturbances from the filling right after placement and none after the 2-year evaluation either.

\section{Discussion}

Although basic restorative dental care is provided for all children in Latvia free of charge through the Sickness Funds and the establishment of Local Oral Health Centres in all districts appears to work well, the caries incidence still remains quite high among children [16] mostly due to fear of dental treatment. The introduction of a new treatment approach raised a positive interest among the parents and the children. However, primary caries lesions in the permanent dentition are not a frequent occurrence, which explains the relatively small number of restorations.

One of the weaknesses of glass ionomer cements is their ability to restore cavities in clinical stress-bearing parts, such as occlusal surfaces. However, many ART studies $[4-10,17]$ have confirmed the advantages of this technique and successful performance of restorations in class I cavities. The test glass ionomer filling was manufactured as a universal glass ionomer filling material also indicated for use with the ART approach. Results of this study are similar to the 1-year results from China [10] showing an apparently positive outcome of the class I ART restorations using the high-strength glass ionomer cement ChemFlex and the Fuji IX GC glass ionomer.

In the present study, there were 2 failures. One probably failed because it was replaced with a different type of filling material by another dentist for unknown reasons. The oth- 
er failed due to the shallow form of the cavity. The wear, which was considered acceptable, was recorded more frequently with the test material than for the control material probably because the number of the test fillings was greater than those of the controls. The presence of fluoride release from the filling material and the hygienic instructions to the subjects may explain the absence of secondary caries or new caries lesions present [18-21]. (All children were also given a new toothbrush and tube of toothpast at the clinical assessments.) No fractures of the restorations were observed in either type of cavities regardless of the material used, control or test. The fact that the restorations did perform well could also be due to the narrow width of the prepared cavity in most of the restorations since usually the cavity remains quite smaller after ART preparation.

According to the ART approach [3] adjacent sound fissures and pits of each involved tooth are sealed using a finger press technique. However, the application of the sealant was not possible for every tooth because of the different sizes of the cavity and tooth anatomy. The drawing of an ART restoration helped the independent examiner to distinguish between the restoration and the sealant. There was no big difference in success rates of $66.7 \%$ for test and $77.8 \%$ for control materials after 2 years; failures may have occurred due to the different mixing consistency of materials (the control material tended to be less viscous). Possible voids in the materials and different shapes of fissures may affect the penetration of material into the deepest parts. However, these results are similar to those obtained in other studies [7-10, 22, 23].

\section{Conclusion}

Regardless of the very small sample sizes, the new glass ionomer filling material has shown a good performance in a 2-year period in terms of retention, marginal failure and fractures in class I restorations. Further assessments are necessary to test the durability of the restorations.

\section{Acknowledgements}

We are grateful for Dr. Sisko Honkala who served as the independent assessor and to Dentsply and GC Corporations who kindly provided the glass ionomer filling materials.

\section{References}

1 Matis BA, Cochran M, Carlson T, Phillips RW: Clinical evaluation and early finishing of glass ionomer restorative materials. Oper Dent 1988;13:74-80.

2 Nicholson JW, Croll TP: Glass-ionomer cements in restorative dentistry. Quintessence Int 1997;28:705-714.

3 Frencken JE, Holmgren CJ: Atraumatic Restorative Treatment for Dental Caries. Nijmegen, STI Book, 1999, pp 17-72.

4 Frencken JE, Songpaisan Y, Phantumvanit P, Pilot T: An atraumatic restorative treatment (ART) technique: An evaluation after one year. Int Dent J 1994;44:460-464.

5 Frencken JE, Makoni F, Sithole WD: Atraumatic restorative treatment and glass-ionomer sealants in a school oral health programme in Zimbabwe: Evaluation after 1 year. Caries Res 1995;30:428-433.

6 Frencken JE, Pilot T, Songpaisan Y, Phantumvanit $P$ : Atraumatic restorative treatment (ART): Rational, technique, and development. J Publ Health Dent 1996;29:1-4.

7 Frencken JE, Makoni F, Sithole WD, Hackenitz E: 3-year survival of ART restorations and glass-ionomer sealants in a school oral health programme in Zimbabwe. Caries Res 1998;32: 119-126.

8 Holmgren CJ, Lo ECM, Hu D, Wan H: ART restorations and sealants placed in Chinese school children - Results after three years. Community Dent Oral Epidemiol 2000;28: 314-320.
9 Phantumvanit P, Songpaisan Y, Pilot T, Frencken J: Atraumatic restorative treatment (ART): A three year community field trial in Thailand - Survival of one-surface restorations in the permanent dentition. J Publ Health Dent 1996;56:141-145.

10 Mandari GJ, Truin GJ, van't Hof MA, Frencken JE: Effectiveness of three minimal intervention approaches for managing dental caries: Survival of restorations after 2 years. Caries Res 2001;35:90-94.

11 ChemFlex High Strength Glass Ionomer (technical manual). Konstanz, Dentsply DeTrey, 1997.

12 Luo Y, Wie SHY, Fan MW, Lo ECM: Clinical investigation of a high strength glass ionomer restorative used in the ART technique in Wuhan, China - One-year results. Chin J Dent Res 1999;2:73-78.

13 Evoldsen N, Covey D, Lavin M: The physical and adhesive properties of dental cements used for atraumatic restorative treatment. Spec Care Dent 1997; 17:19-24.

14 Smales RJ, Gao W, Ho F: In vitro evaluation of sealing pits and fissures with newer glass-ionomer fillings cements developed for the ART technique. J Clin Pediatr Dent 1997;21:321323.

15 Frencken CE, Holmgren CJ: How effective is ART in the management of dental caries? Community Dent Oral Epidemiol 1999;27: 423-430.
16 Care R, Urtane I, Senakola E: Caries decline in 6- to 15-year-olds in Riga City (Latvia) due to introducing preventive programmes. J Eur Org Caries Res (ORCA) 1999;33:287-289.

17 Pitiphat W, Phantumvanit P, Songpaisan Y, Frencken J, Pilot T: Atraumatic restorative treatment technique (ART): Evaluation after two years (abstract 24). J Dent Res 1994;73: 1014.

18 Koch G, Hatibovic-Kofman S: Glass ionomer cements as a fluoride release system in vivo. Swed Dent J 1990;14:267-273.

19 Forsten L: Short- and long-term fluoride release from glass ionomers and other fluoride containing filling materials in vitro. Scand $\mathbf{J}$ Dent Res 1990;98:179-185.

20 Benelli EM, Serra MC, Rodrigues AL Jr, Cury JA: In situ anticariogenic potential of glass ionomer cement. Caries Res 1993;27:280-284.

21 Varpio M, Noren JG: Artificial caries in primary and permanent teeth adjacent to composite resin and glass ionomer cement restorations. Pediatr Dent 1994;16:107-109.

22 Widmer RP, Jayasekera TR: Fissure filling with a glass ionomer cement: 2-year results. J Dent Res 1989;68:53.

23 McKenna EF, Grundy GE: Glass ionomer fissure sealants applied by operative dental auxiliaries - Retention rate after one year. Aust Dent J 1987;32:200-203. 